\title{
Influence of Straight Nozzles on Fluid Flow in Mold and Billet Quality
}

\author{
E. TORRES-ALONSO, R.D. MORALES, S. GARCIA-HERNANDEZ, \\ A. NAJERA-BASTIDA, and A. SANDOVAL-RAMOS
}

\begin{abstract}
Flux entrainment defects in a billet mold with two straight nozzles (outer radius of $60 \mathrm{~mm}, \mathrm{~S} 60$, and $73 \mathrm{~mm}, \mathrm{~S} 73$, and same interior radius of $36 \mathrm{~mm}$ ) are studied using mathematical simulations and experimental techniques including particle image velocimetry (PIV), tracer injection, and water-oil modeling. Experimental findings indicated that using either of these nozzles at the deepest position of $135 \mathrm{~mm}$ (measured from the nozzle tip to the meniscus level) induces a flow near the meniscus, characterized by low turbulence yielding very stable water-oil interfaces. Simultaneously, owing to the mold radius, the entry jet induces a nonsymmetric flow downstream in the mold. At the shallow position of $90 \mathrm{~mm}$, nozzle S73 induces a flow characterized by cyclic velocity spikes of low frequency and short duration close to the meniscus making the metal-flux interface highly instable. As the gap between the nozzle outer wall and the mold face is narrower and the nozzle position is shallower, the fluid close to the meniscus develops zones of high vorticity gradients leading to rotating flows, which are responsible for that instability. Water-oil experiments indicated that during the generation of this phenomenon, water flow entrains oil droplets in the side of the mold inner radius. Instability of metal-flux interface is then a consequence of the fluctuating nature of the recirculating flows in the mold, which induce upper rotating flows with large vorticity gradients. This mechanism explains actual flux entrainment defects in a billet caster.
\end{abstract}

DOI: $10.1007 / \mathrm{s} 11663-008-9202-2$

(C) The Minerals, Metals \& Materials Society and ASM International 2008

\section{INTRODUCTION}

ALL casters are aware of the importance of the fluid flow effects on superficial and internal quality of steel, originating many publications particularly related with the influence of submerged entry nozzles on steel flow in slab molds. ${ }^{[1-10]}$ Fewer publications related with fluid flow in billet molds and particle image velocimetry (PIV) measurements are available, ${ }^{[1-15]}$ probably because the conventional straight nozzles employed in this field work in a much more confined space, inducing what would be called standard flows with small variations of fluid flow patterns. However, the study presented here made clear that the complex nature of turbulent flows prevails even under the conditions of very stable flows, such as those expected in billet molds. Specifically, the case treated in this work corresponds to a caster in Mexico, hereinafter called simply Company "A," which operates a four-strand billet caster. Ladle capacity is 70 tons of steel that transfers the metal to a delta-shaped tundish with a capacity of 18 tons. Billet section is $160 \times 160 \mathrm{~mm}$ and Figures 1(a) through (c) show the

E. TORRES-ALONSO, S. GARCIA-HERNANDEZ, and A. NAJERA-BASTIDA, Graduate Students, and A. SANDOVALRAMOS, Researcher, are with Department of Metallurgy, Instituto Politécnico Nacional-ESIQIE, Mexico D.F., CP 07738, Mexico. R.D. MORALES, Professor, Department of Metallurgy, Instituto Politecnico Nacional-ESIQIE, is President, K\&E Technologies, And. 8 No. 7 Col. El Risco-CTM, México D.F., CP 07079, Mexico. Contact e-mail: rmorales@ipn.mx

Manuscript submitted November 20, 2007.

Article published online November 15, 2008. mold geometry. Machine radius is $7418 \mathrm{~mm}$ and the mold corners have a radius of $4 \mathrm{~mm}$. Production mix includes all sorts of low-alloy special steels including $\mathrm{Cr}$, $\mathrm{Cr}-\mathrm{Ni}, \mathrm{Cr}-\mathrm{Ni}-\mathrm{Mo}$, and $\mathrm{Cr}-\mathrm{V}$ grades as well as medium carbon steels used for heat-treated automotive components. Steel refining in Company A is carried out through the EAF-LF-VD route. Average monthly production is 35,000 tons yielding a production of steel per year of 420,000 tons. Steel feeding into the molds is performed indistinctly through straight nozzles with the same internal diameter of $36 \mathrm{~mm}$; the only difference among them is their outer diameters, which are 60 and $73 \mathrm{~mm}$, as is seen in Figures 2(a) through (b). These nozzles are called S60 and S73, respectively. Minimum and maximum nozzle operating submergences of these nozzles are 90 and $135 \mathrm{~mm}$ measured from the meniscus level to the nozzle tip. Lubrication powder employed in the mold has the chemistry shown in Table I. The problem hindering the billet quality was the irregular but permanent entrainment of flux into the metal bulk, as was proved through chemical mappings obtained by a scanning electron microscope (SEM). Figures 3(a) through (f) show a secondary electron image of one of these macroinclusions and the corresponding chemical mappings where the presence of sodium is abundant, demonstrating the mold powder as the origin of such defects. Spent nozzles presented the usual corrosion belts on the outer surface. Visual inspection and chemical analysis indicated that flux-slag drained off along the surface until reaching the nozzle tip and flowing countercurrent, by Marangoni effects, against 


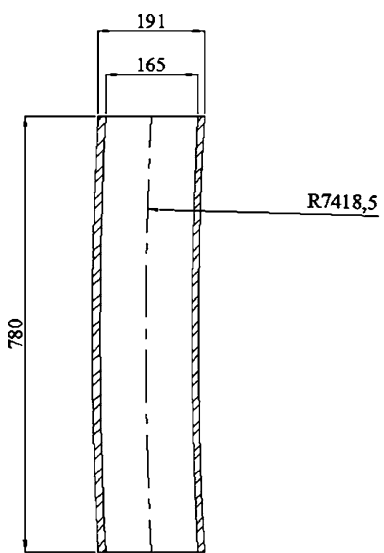

(a)

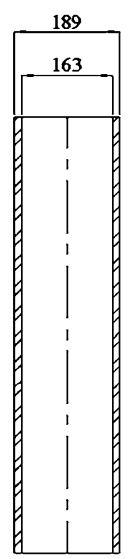

(b)

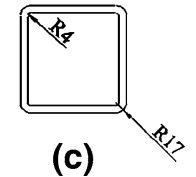

(c)

all dimensions in $\mathrm{mm}$
Fig. 1-Dimensions of billet mold: $(a)$ lateral view, $(b)$ frontal view, and $(c)$ top view.

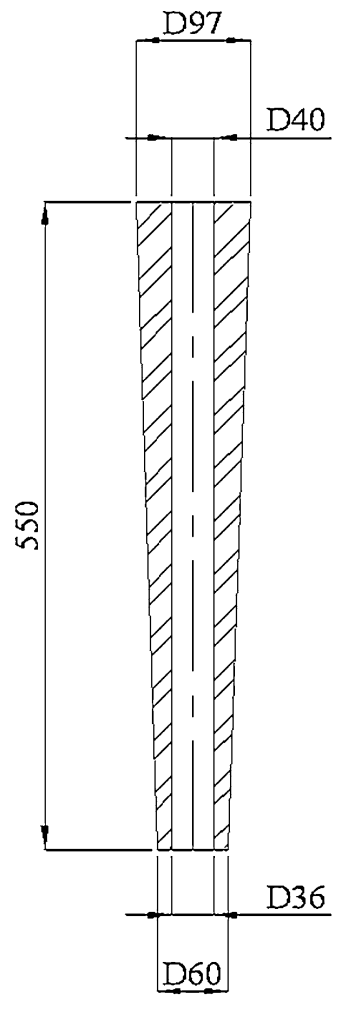

(a)

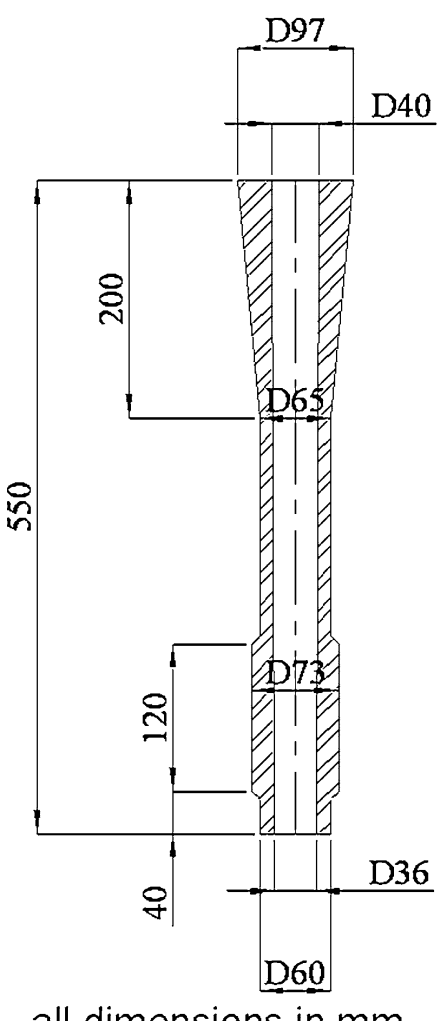

all dimensions in $\mathrm{mm}$

(b)
Fig. 2-Dimensions of straight mold nozzles: (a) nozzle S60 and (b) nozzle S73.

steel flow inside the nozzle until a distance of about $0.05 \mathrm{~m}$ from the tip.

Figure 4 shows the aspect of spent nozzles and Figures 5(a) through (f) show a SEM image of the deposit and the corresponding chemical mappings where sodium is again abundant. The scheme in Figure 6 indicates the position of these macroinclusions in rolled bars $(\varphi=50.8 \mathrm{~mm})$ and the corresponding original
Table I. Chemistry and Physical Properties of Mold Flux

\begin{tabular}{|c|c|c|c|}
\hline \multicolumn{4}{|c|}{ Mold Flux } \\
\hline \multicolumn{2}{|c|}{ Chemical (Pct) } & \multicolumn{2}{|c|}{ Physical Properties } \\
\hline $\mathrm{CaO}$ & 20.1 & density & $2600 \mathrm{~kg} \mathrm{~m}^{-3}$ \\
\hline $\mathrm{Al}_{2} \mathrm{O}_{3}$ & 4.7 & $\begin{array}{l}\text { interfacial tension } \\
\text { molten steel flux }\end{array}$ & $1.3 \mathrm{~N} \mathrm{~m}^{-1}$ \\
\hline $\mathrm{SiO}_{2}$ & 33.3 & viscosity (Iida model) & $0.47 \mathrm{~Pa} \mathrm{~s}$ \\
\hline $\mathrm{MgO}$ & 2.0 & thermal conductivity & $1.0 \mathrm{~W} \mathrm{~m}^{-1} \mathrm{~K}^{-1}$ \\
\hline $\mathrm{Fe}_{2} \mathrm{O}_{3}$ & 0.3 & - & - \\
\hline $\mathrm{Na}_{2} \mathrm{O}$ & 8.8 & 一 & - \\
\hline $\mathrm{F}$ & 5.9 & - & 一 \\
\hline $\mathrm{C}$ & 16.9 & 一 & - \\
\hline
\end{tabular}

location in the billet. Indeed, a constant characteristic is that the defect always appeared as a group of macroinclusions conforming a spot located 0.5 to $1.5 \mathrm{~mm}$ below the bar surface. There were not other groups of macroinclusions in the cross section of the bar. However, at this stage of preliminary inspection it was not possible to define which of the original billet faces was associated with this defect. The problem was sometimes very frequent (on a daily basis), and during other periods it simply did not show up, thus following a very irregular pattern. A first attempt trying to link the appearance of the defect with the caster's operating parameters included a statistical analysis but this approach was unsuccessful. Therefore, Company A together with our group started an investigation to find out the reason behind this irregular behavior. Since it was evident that the problem was fluid flow related, the second attempt to find its source included the use of mathematical simulations through a Computer Fluid Dynamics (CFD) approach and water model experimentations of fluid flow in the mold.

\section{WATER MODEL OF A BILLET MOLD AND MATHEMATICAL MODEL}

The experimental approach includes a billet mold and the two nozzles, S60 and S73, made of transparent plastic all with full-scale geometry corresponding to the industrial system. The end of the mold has a flange that fits with the upper edge of a water deposit by means of a slit, which has an O-ring inside. A silicon glum seals the juncture between the mold and the water deposit. A valve controls water flow rate measured by a digital flow meter located in the pipe; water discharges into the mold and drains through its bottom closing the hydraulic loop. Particle image velocimetry equipment helped to characterize fluid flow dynamics. Detailed descriptions of this technique can be found in the book of Raffel et $a l .^{[16]}$ Main areas of investigation included the upper part of the mold from the meniscus to the nozzle tip and the jet, which exits into the mold. Figure 7 shows a photo of the plastic mold and Figure 8 shows a scheme of the complete experimental setup. Additional experiments consisted in the injection of a red dye tracer in the upper part of the nozzle to observe the expansion of the jet as well as the mixing patterns recorded by a digital 

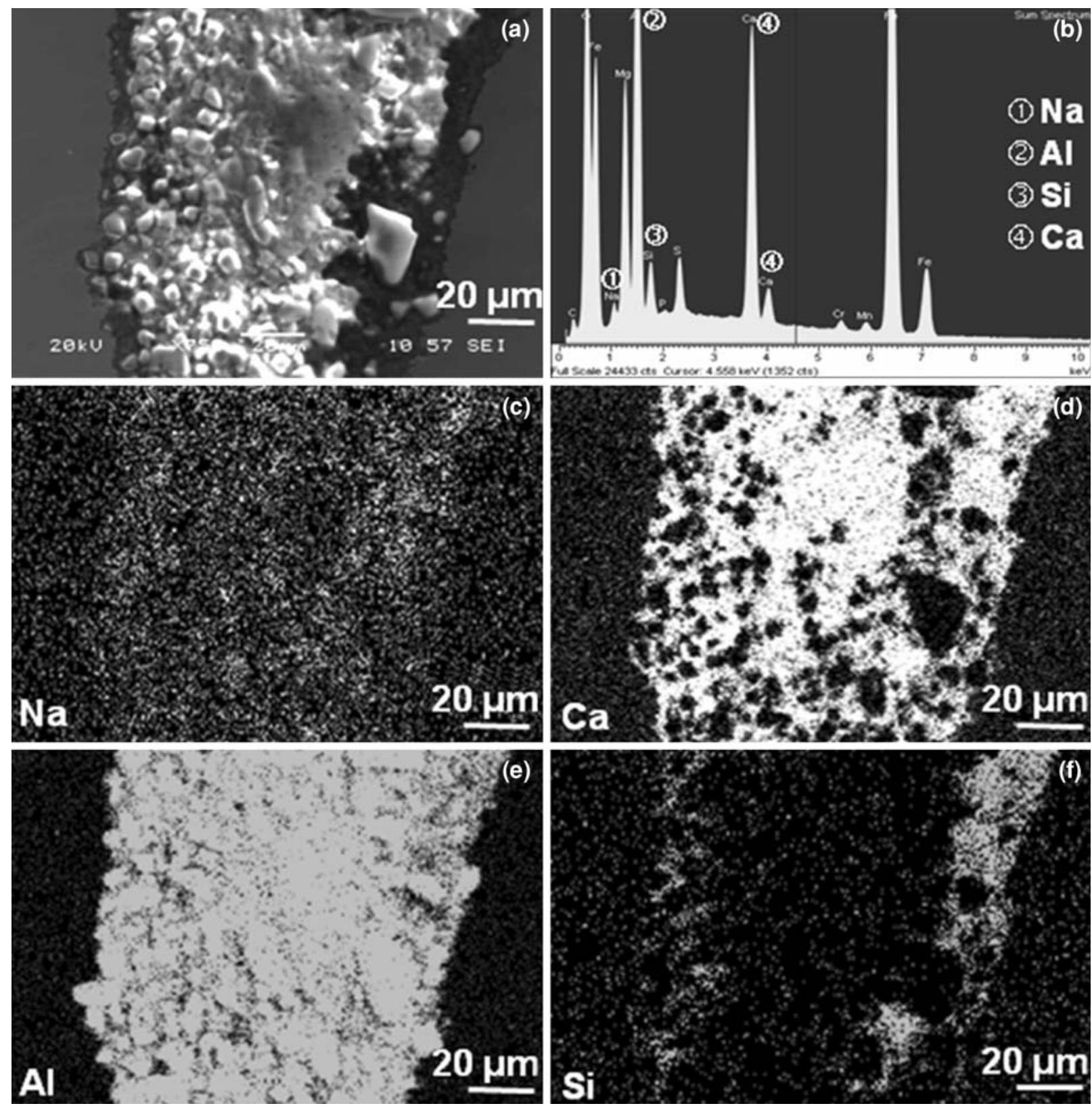

Fig. 3-Chemical maps of macroinclusions in the billet. Fundamentally composed of alumina inclusions combined with entrainment of mold flux.

video camera. Other types of experiments consisted of using a silicon oil layer on the water surface and recording also by video the water-oil interface. This simple experiment allowed the direct observation of this interface by video recordings during a time of approximately 7 minutes. Scales located in the central parts of the mold faces allowed recording the meniscus variations during the experimentation times. The experimental runs included the two nozzles at submersion depths of 90 and $135 \mathrm{~mm}$ at a fixed casting speed of $1.3 \mathrm{~m} / \mathrm{min}$ of molten steel equivalent to $35.4 \mathrm{~L} / \mathrm{min}$ of water in the model.

For mathematical modeling of fluid flow-dynamics in the billet mold, the traditional $k-\varepsilon$ model of Jones and Launder ${ }^{[17]}$ is suitable. The reason behind this choice is based on the simplicity of this model, its capability to predict acceptably well complex engineering flows, ${ }^{[18-20]}$ and its widespread knowledge by the fluid mechanics community. Essentially, the model consists of simultaneously solving the continuity, momentum, kinetic energy, and dissipation rate of the kinetic energy equations. Since it is not possible to directly solve the Reynolds stresses use is made of the Boussinesq hypothesis for relating them with the averaged velocity gradients. Velocity fields provided by this model are time averaged and it is part of the family of models known as Reynolds average Navier-Stokes (RANS).

A computational nonstructured mesh of the physical domain of the mold involving 700,000 cells was built and the criterion of convergence is that the sum of 


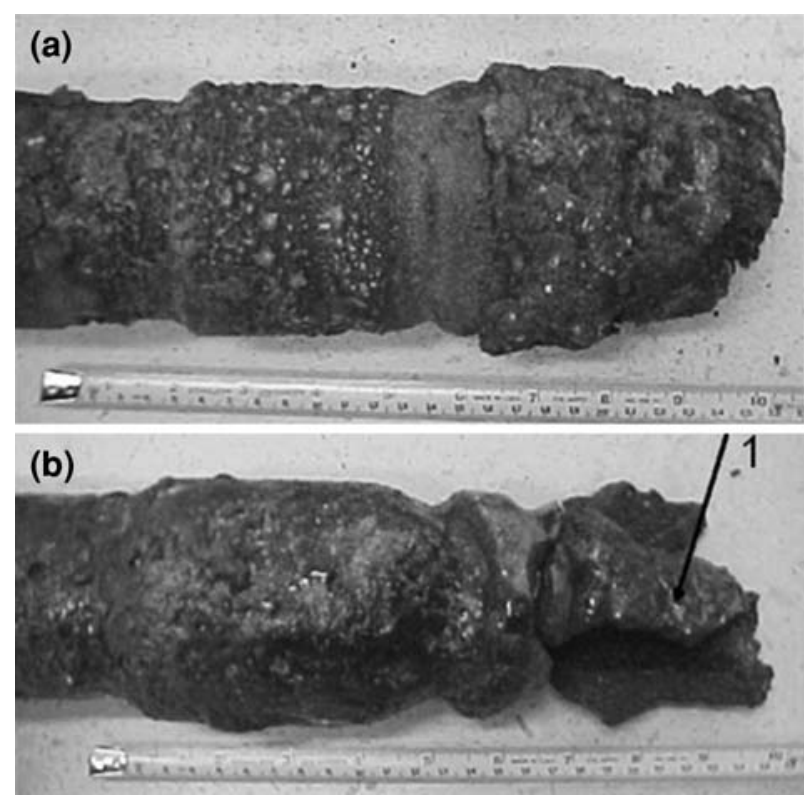

Fig. 4-Physical aspects of two spent nozzles. (a) Wearing belts due to corrosion of nozzle material with mold flux. (b) Number 1 indicates position of the mold flux, which flows even inside the nozzle in countercurrent with the molten steel.

residuals of all flow variables must be less than $10^{-5}$. Unsteady-state solutions of RANS equations are useful for simulating fluid dynamics and this is the approach used here. The computational mesh, partially presented in Figure 9, includes from the top of the mold to a level located $0.15 \mathrm{~m}$ below the mold end. In the first step of the simulation program, only flow of water in the model including the air layer located above the meniscus until the mold top is included. The water-air interface was simulated using the volume of fluid model, ${ }^{[21]}$ which solves only one set of continuity and momentum equations and the interfacial computational cells are shared by both phases, water and air. The boundary conditions used in this model include no-slip flow in all solid surfaces, a velocity profile in the nozzle that follows the $1 / 7$ distribution law for flows in pipes, ${ }^{[22]}$ and a continuous momentum transfer profile at the liquidgas interface. A velocity boundary condition is applied at the end of the computational domain located slightly below the mold end.

The RANS equations and their closure equations were solved using the staggered mesh approach of Patankar in his algorithm SIMPLER ${ }^{[23]}$ Computed flow fields at every 20 seconds were stored in the computer's hard disk for further analysis and discussion. For process analysis and process diagnosis, these simulations included 10 minutes of real time and the averaged flow fields obtained during this period are assumed as representatives of the steady-state flow conditions. However, the examination of any unsteady flow was always possible by reviewing the stored file in the computer hard disk. Moreover, using a multiphase fluid flow and heat-transfer models, explained subsequently in this article, flux infiltration between the mold hot face and the shell was also simulated. Table II shows the physical properties of water, air, and liquid steel involved in the CFD simulations.

\section{RESULTS AND DISCUSSION}

Figure 10 shows the mixing pattern at different times after the injection of the red dye tracer using the nozzle S60 submerged at $90 \mathrm{~mm}$ from a view corresponding to lateral mold face parallel to its radius. Just after 1 second, the jet expands downstream following a nonsymmetric flow. This nonsymmetric flow comes from effects of the radius of curvature of the mold. After 2 seconds the flow asymmetry is more evident as the tracer mixes well close to the inner radius mold face, while mixing in the other side belonging to the outer mold radius face is still poor. After 5 seconds the tracer mixes unevenly and preferably through the gap located between the internal mold face and nozzle wall, and finally at 7 seconds the tracer is near to being completely mixed in the side of the inner radius mold face, while in the side of the outer radius mold face mixing process continues. After 1 second of the tracer injection (using nozzle S60 at a submergence of $135 \mathrm{~mm}$, Figure 11), the jet expands due to the entrainment of the surrounding liquid, and its front reaches a deeper position due to the larger nozzle submergence. Although the asymmetric flow prevails, it is clear that after 2 seconds the tracer yields better mixing in the side of the inner radius mold face. After 5 seconds, the mixing ends with a rather sharp front that is reaching the nozzle tip. The main difference comes after 7 seconds when the diffusion of tracer takes a preferable avenue through the gap between the nozzle wall and the outer radius mold face. Visual observations of the upper side of mold in the region from the nozzle tip to the meniscus indicated the presence of a very quiet flow and a flat meniscus, which looked apparently undisturbed under all experimental conditions studied here. Tracer experiments related with nozzle S73 for both submergences looked very similar to the previous description for nozzle S60, and any further evidence about the problem could not, unfortunately, be obtained using this technique. Therefore, it is evident that an additional analysis of the flow is necessary to define the source of entrainment of flux inclusions, and part of the answer was examined through CFD simulations.

Figures 12(a) through (d) show the velocity fields of water inside the plastic mold for nozzles S60 and S73 at submergences of 90 and $135 \mathrm{~mm}$ in the central symmetric plane. In both cases, these views correspond to the lateral mold face (same as the tracer images presented in Figures 10 and 11). As seen in any case, velocity fields are clearly asymmetric because of the radius of curvature of the caster, as was mentioned previously. In the side of the interior mold radius, the jet boundary shears the surrounding water transferring momentum downstream, thus contributing to its expansion and to faster mixing of the tracer. In the side of the outer radius mold face there is a long recirculation flow formed by a downward stream of relatively high velocity due to the dragging effects of the entry jet on the surrounding water. The recirculation is completed by a high upstream velocity flow along the outer mold face. 

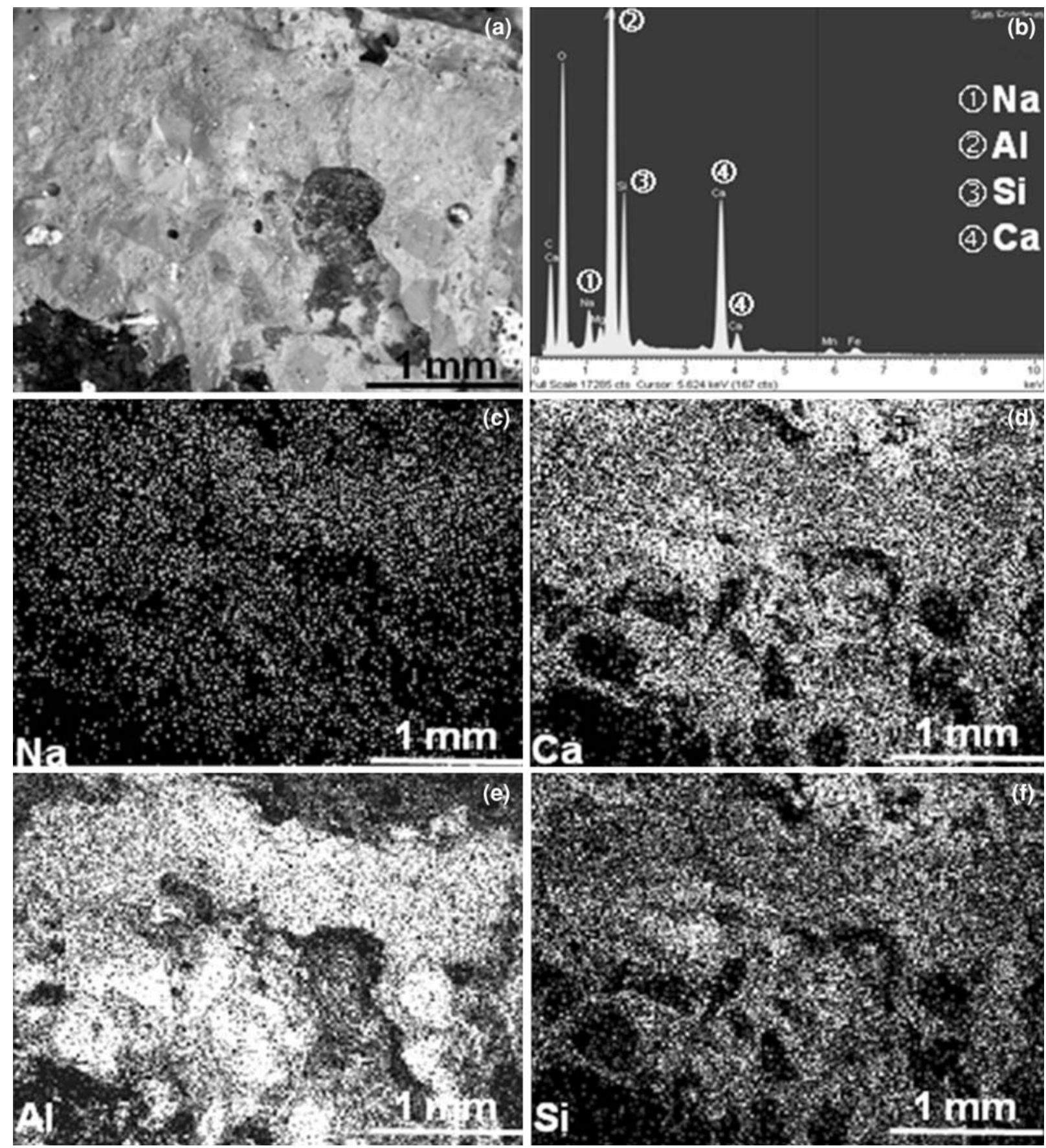

Fig. 5-Chemical mappings of slag attached to outer side of nozzle.

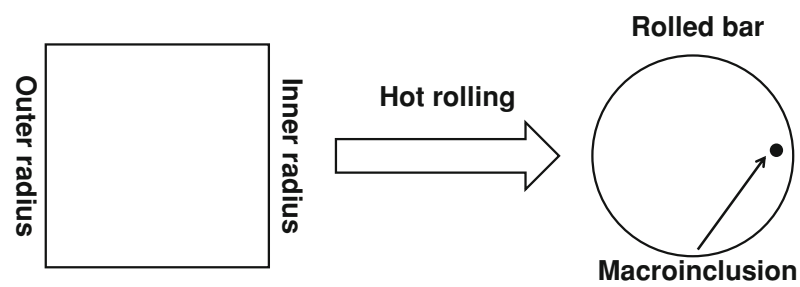

Fig. 6-Cross section of a steel bar with macroinclusions in the bottom side indicated by the mark. Square indicates position of defect with respect to faces of the mold.

The existence of this recirculating flow explains the slower tracer mixing kinetics observed in Figures 10 and 11 in the upper side of the outer mold radius face. Below the jet, water adopts a plug flow until the mold end. The upper mold region located in the distance between the nozzle tip and the meniscus shows the presence of a very quiet flow, visually observed, during the experimental runs. Apparently, water rotates around the nozzle with velocities that are one order of magnitude smaller than those observed in the region influenced by the entry jet. Close observations of these results do not yield 


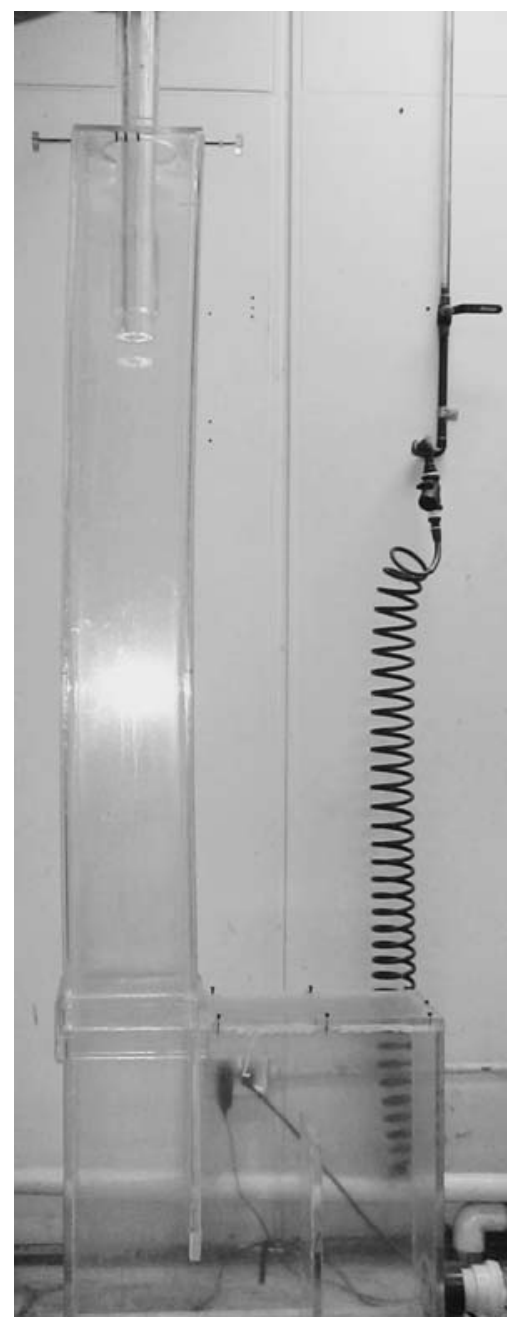

Fig. 7-Plastic mold model with the nozzle in the top.

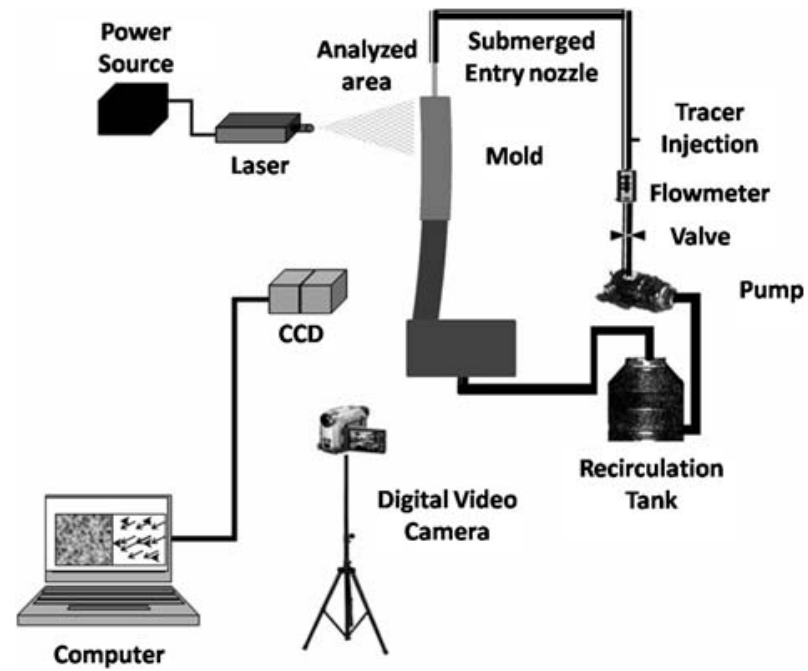

Fig. 8- Scheme of full experimental setup.

appreciable differences of fluid flow patterns between the two nozzles at the same submergences. Therefore, subsequent observations included perpendicular planes

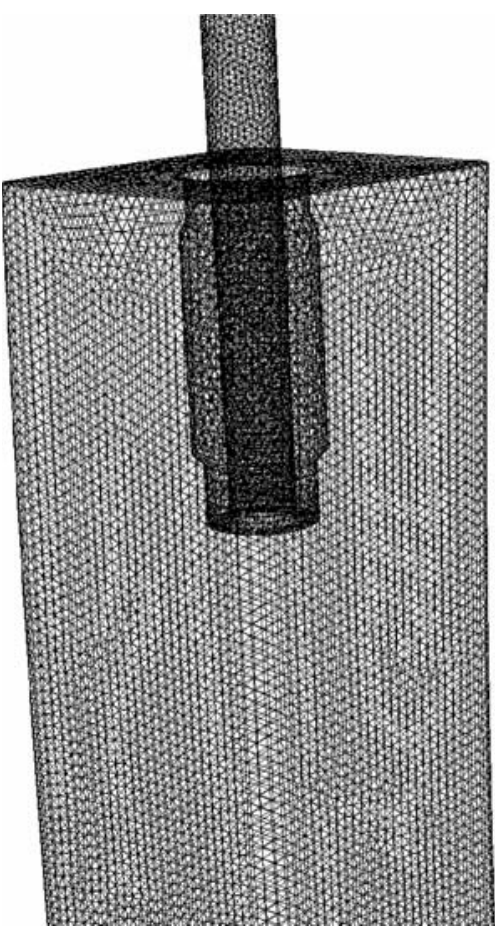

Fig. 9-Unstructured computational mesh, including mold and nozzle.

Table II. Physical Properties of Water, Steel, and Air

Steel properties*

Thermal conductivity $\left(\mathrm{W} \mathrm{m}^{-1} \mathrm{~K}^{-1}\right.$ )

32.7

Density $\left(\mathrm{kg} \mathrm{m}^{-3}\right)$

Viscosity $\left(\mathrm{kg} \mathrm{m}^{-1} \mathrm{~s}^{-1}\right)$

8586 to $0.8567 \mathrm{~T}$

Melting heat $\left(\mathrm{J} \mathrm{kg}^{-1}\right)$

0.0064

Liquidus $(\mathrm{K})$

250,000

1787.5

Solidus (K)

1724

Water properties at room temperature

Viscosity (Pa s)

0.001

Density $\left(\mathrm{kg} \mathrm{m}^{-3)}\right.$

1000

Surface tension $(\mathrm{N} / \mathrm{m})$

0.075

Air properties

Thermal conductivity of air $\left(\mathrm{W} \mathrm{m}^{-1} \mathrm{~K}^{-1}\right) \quad 0.06$

Density $\left(\mathrm{kg} \mathrm{m}^{-3}\right) \quad 1.225$

Viscosity $\left(\mathrm{kg} \mathrm{m}^{-1} \mathrm{~s}^{-1}\right) \quad 1.789 \times 10^{-5}$

*Steel chemistry (resulfurized steel) in mass pct: $\mathrm{C}=0.07, \mathrm{Mn}=$ 1.12 pct, $\mathrm{Si}=0.03$ pct, $\mathrm{P}=0.05$ pct, $\mathrm{S}=0.3$ pct, $\mathrm{Cr}=0.15, \mathrm{Ni}=$ 0.1 pct, $\mathrm{Mo}=0.025, \mathrm{Al}=0.003$ pct, and $\mathrm{Cu}=0.22$ pet.

to the mold radius, located close to the inner and outer mold faces at a submergence of $90 \mathrm{~mm}$.

Figures 13(a) and (b) show velocity fields close to the inner and outer mold radius faces, respectively, with the nozzle S60 at a depth of $90 \mathrm{~mm}$. Figures 13(c) and (d) correspond to a submergence of $135 \mathrm{~mm}$ for planes close to the inner and outer mold radius faces, respectively. In both cases, close to the internal face (inner mold radius) water flows with relatively high velocities along the mold corners and ascends until the level of the nozzle tip, where it turns toward the center of the mold. In the central region of this plane, the flow is very complex because there is a descending stream driven by the 


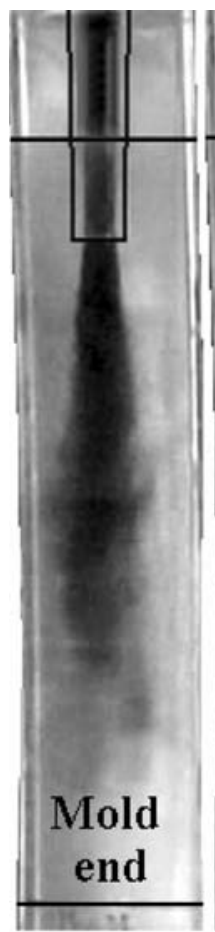

$1 \mathrm{~s}$

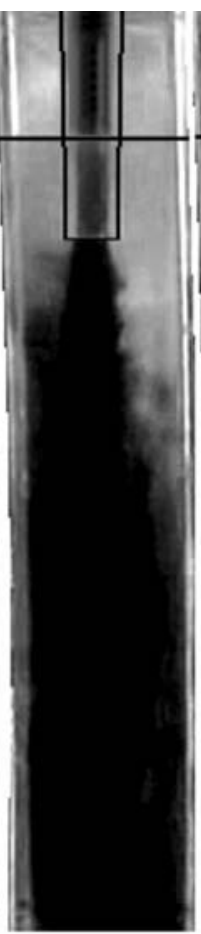

$2 \mathrm{~s}$

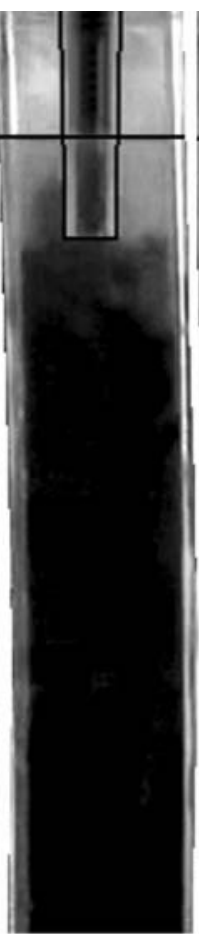

$5 \mathrm{~s}$

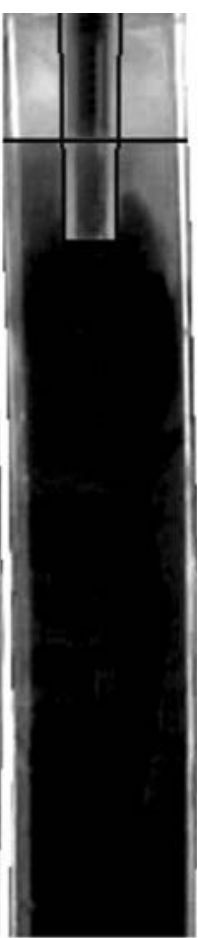

$7 \mathrm{~s}$

\section{Time}

Fig. 10-Mixing patterns of red dye tracer using nozzle S60 with a submergence of $90 \mathrm{~mm}$.

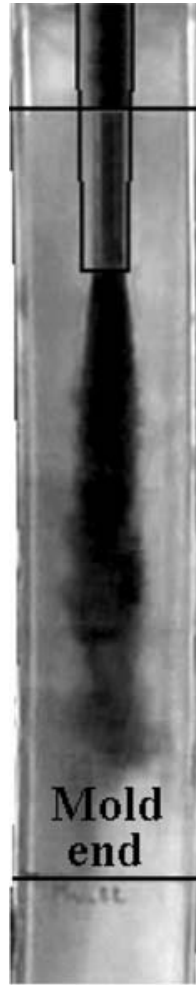

$1 \mathrm{~s}$
$2 \mathrm{~s}$

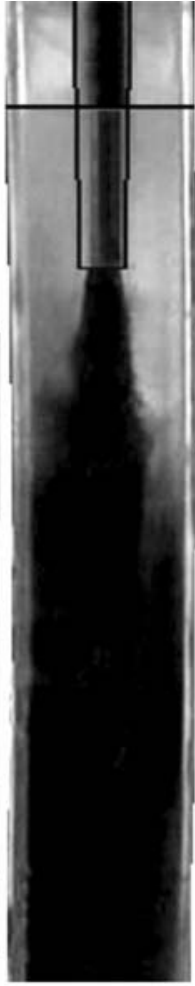

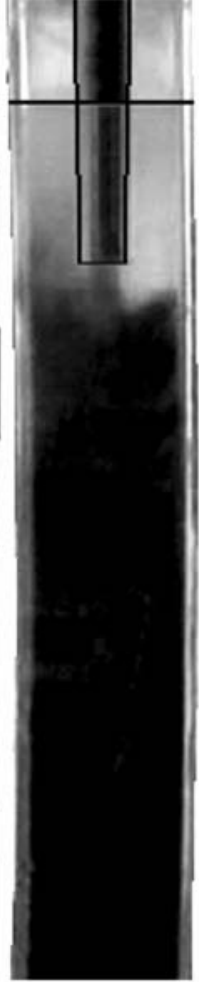

$5 \mathrm{~s}$

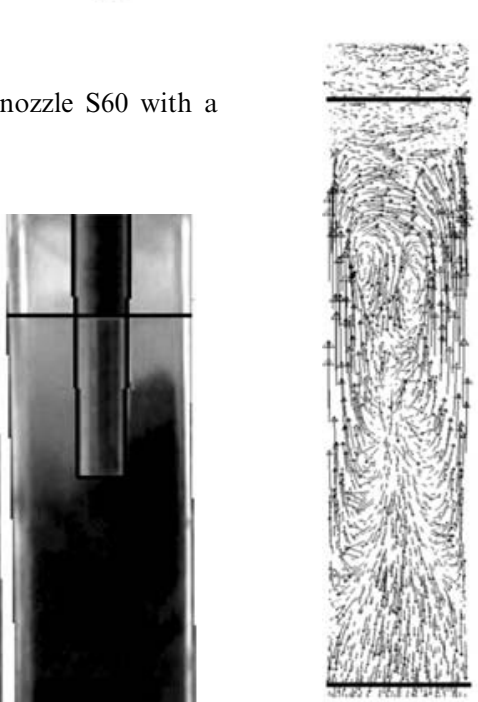

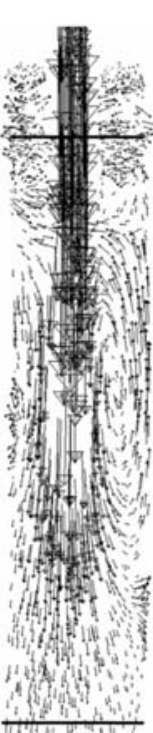

(a)

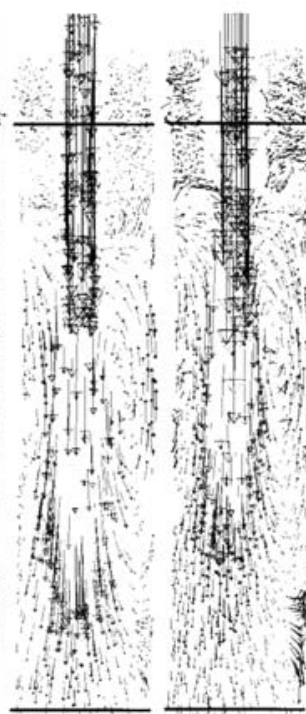

(b)

(c)

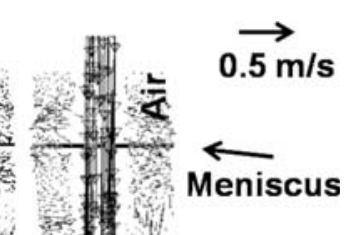

Fig. 12 - Computed velocity fields at central-symmetric plane parallel to the lateral mold face: (a) S60 90-mm immersion, (b) S60 135-mm immersion, (c) S73 90-mm immersion, and (d) S73 135-mm immersion. (a)

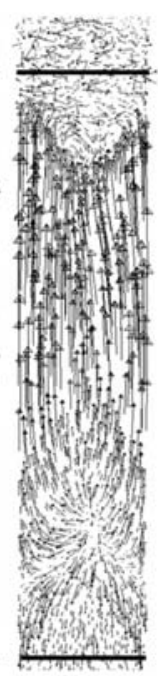

(b)

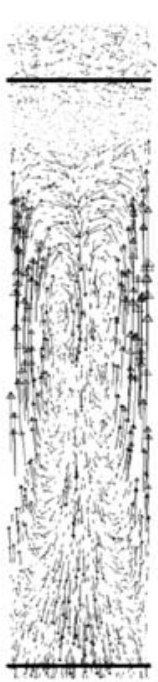

(c)

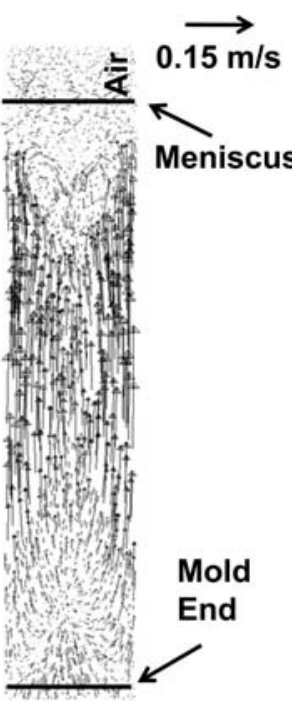

(d)
Fig. 13-Computed velocity fields with $\mathrm{S} 60$ at different planes: (a) near the inner radius, 90-mm immersion; (b) near the outer radius, 90 - $\mathrm{mm}$ immersion; $(c)$ near the inner radius, $135-\mathrm{mm}$ immersion; and $(d)$ near the outer radius, $135-\mathrm{mm}$ immersion.

gravity force that is sheared by the two ascending streams in the mold corners, inducing a chaotic velocity field with vectors in all directions.

Further down the mold, gravity force completely dominates momentum transfer and water descends following a plug flow pattern. In the plane close to the external face (outer mold radius) flow is simpler; water is mostly ascending due to the existence of the long recirculating flow until it reaches the upper region, and then turns to the center of the mold. Close to the mold
Fig. 11-Mixing patterns of red dye tracer using nozzle S60 with a submergence of $135 \mathrm{~mm}$. 
end, there is a region where the ascending flow (driven by the recirculating flow induced by the jet) and the descending flow (driven by gravity) separate to give place to the descending plug flow mentioned previously. As seen in these figures, the effects of the nozzle position apparently does not produce any appreciable difference of flow in the inner plane, with the exception of a slightly higher transition zone that separates the ascending flow from the rotating flow close to the meniscus for the shallow nozzle position. In the outer plane, the shallower nozzle position makes the higher velocity of the ascending stream reach a level closer to the meniscus, reducing the volume of the rotating flow located in this region.

Therefore, the net macroscopic effect of the nozzle position is that at submergence of $90 \mathrm{~mm}$, the volume of the rotating fluid flow is slightly reduced compared with the submergence of $135 \mathrm{~mm}$. Although the same analysis was performed using nozzle S73, no substantial difference was found with the description made for nozzle S60 and, consequently, those flows do not require further discussion. The next step in the present analysis was the examination of flows in a horizontal plane close to the meniscus level $(40 \mathrm{~mm})$.

Figures 14(a) and (b) show these flows for nozzle S60 at submergences of 90 and $135 \mathrm{~mm}$, respectively, and in Figures 14(c) and (d) for nozzle S73 at the same submergences. In the case of the same shallow nozzle submergence (Figures 14(a) and (c)), there are regions with flows of relatively high velocity, of the order of $0.15 \mathrm{~m} / \mathrm{s}$, emerging from the mold corners in the side of the inner radius. Using nozzle S73 these high-velocity regions are visibly larger than in the case of using nozzle S60. In this later case, a high-velocity flow only partially impacts the nozzle wall, inducing a rotating flow in the side of the outer radius mold face. Different from nozzle

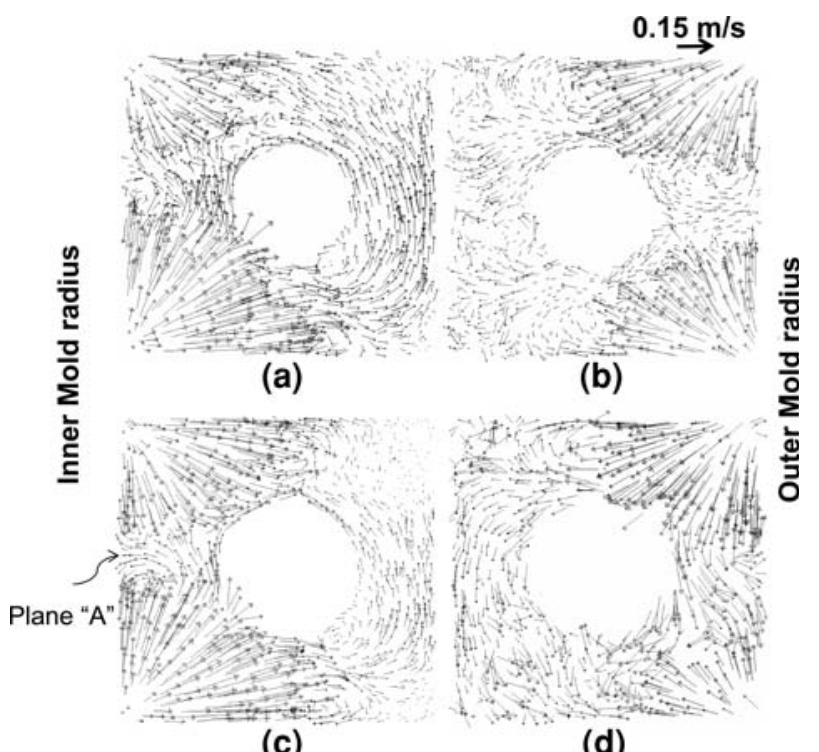

(c)

(d)

Fig. 14 Computed velocity fields in a horizontal plane $20 \mathrm{~mm}$ from the meniscus: (a) S60 90-mm immersion, (b) S60 35-mm immersion, (c) S73 90-mm immersion, and (d) S73 135-mm immersion.
60 , nozzle S73 provides a more complex flow since the high-velocity flows emerge from both corners of the mold and impinge on the nozzle wall with the same intensity. This impact on the nozzle forms a weak rotating flow in the back close to the outer mold face. Moreover, both corner flows meet just in front of the nozzle wall forming a complex vortex flow of small velocities marked with the letter A in Figure 14(c). It can be said that nozzle S73, due to its larger outer diameter, leaves a narrower space between its wall and the inner mold face, intensifying the flow phenomenon described here. This particular flow makes the meniscus more instable; meanwhile, when nozzle S60 is used, the flow simply remains rotating (Figure 14(a)).

Reviewing the computer files, it was possible to know that those high-velocity regions, when both nozzles are located in the shallow position, shifted sometimes to the corners of the outer mold face to come back again to the side of the inner radius mold face remaining in the majority of the casting time in this position. When both nozzles are at submergence of $135 \mathrm{~mm}$, the high-velocity flows emerge during the full casting time from the mold corners in the outer mold radius side (Figures 14(b) and (d)), generating simply rotating velocity fields. Generally speaking, the sizes of these regions of high-velocity flows are smaller than those observed when the nozzle is at the shallow position. These results indicated that nozzle S60 provides stable rotating flows at both nozzle submergences, while nozzle S73 induces a complex flow in its front side inner radius mold face at its shallow position. This complex flow located between the mold face and the nozzle wall in the inner radius side is probably the origin of the flux entrainment problem into the steel bulk in the actual caster.

Since the flows observed in the horizontal planes close to the meniscus shed for the first time a clue about the source of flux entrainment related with fluid flow, the next step was to analyze PIV measurements of water velocity in the entry jet and in the rotating region close to the meniscus, complementing the information provided by CFD simulations. Figures 15(a) through (d) show the velocity vectors of water in the entry jet in the central-symmetric plane parallel to the mold radius, lateral view, with a difference of 1 second between each image for nozzle S73 at a submergence of $90 \mathrm{~mm}$.

The jet reported slight oscillations due to the turbulent conditions, but there was not any evidence that would lead to any conclusion. The second analysis using PIV measurements included the central-symmetric plane parallel to the mold radius in the upper complex flow region located between mold inner face and the nozzle wall (letter A in Figure 14c, this plane is perpendicular to the sheet of this paper). Indeed, there are important differences detected between the performances of both nozzles. Figures 16(a) through (d) show the instantaneous velocity fields at arbitrary times of $0,1,2$, and 3 seconds, respectively, using nozzle S60 at a depth of $90 \mathrm{~mm}$. These flows show a strong dependence on time. There are clearly back flows in the nozzle tip as the CFD predictions indicate in Figures 12(a) through (d). In the region that is very close to the meniscus, water velocity is very small maintaining practically stagnant conditions. 


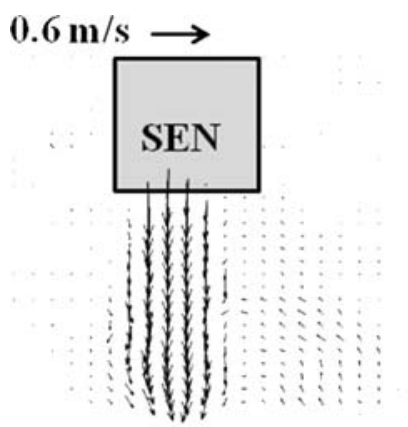

(a)

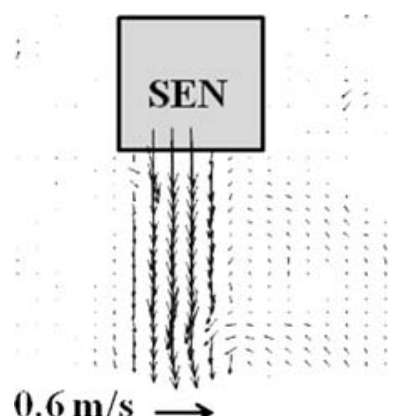

(c)

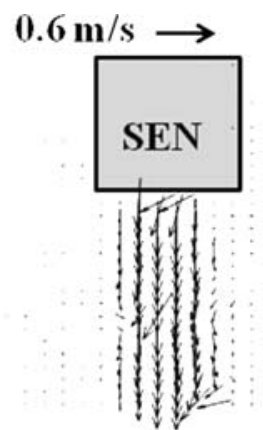

(b)

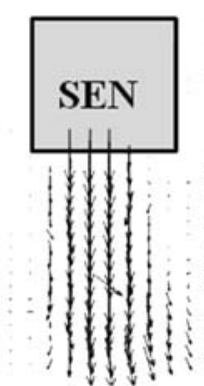

$0.6 \mathrm{~m} / \mathrm{s} \longrightarrow$

(d)
Fig. 15-Instantaneous velocity vectors measured by PIV, S73 90-mm immersion. There is a second between each $(a)$ through $(d)$.

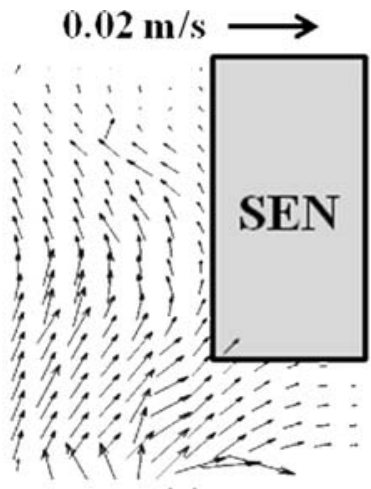

(a)

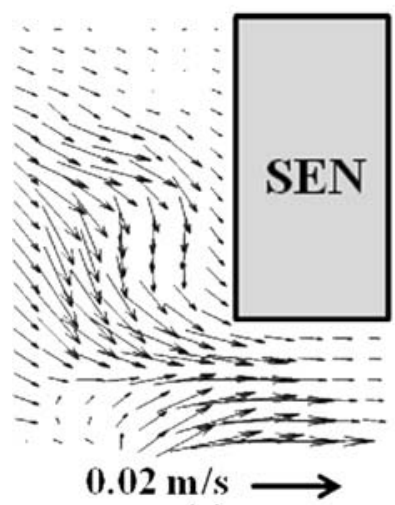

(c)

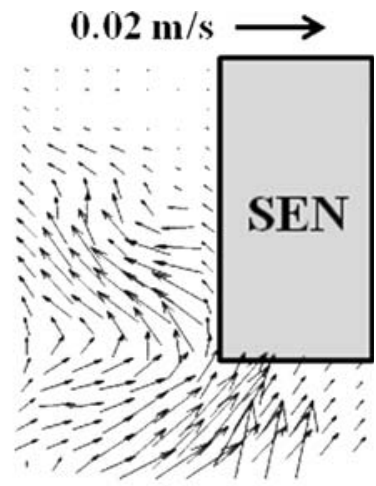

(b)

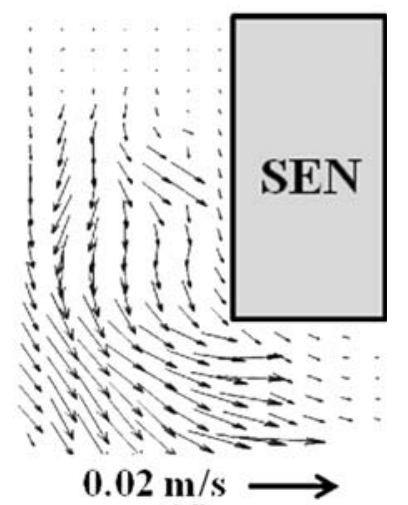

(d)
Fig. 16-Instantaneous velocity vectors measured by PIV, S60 $90-\mathrm{mm}$ immersion. A central-symmetric plane perpendicular to the radius. There is a second between each $(a)$ through $(d)$.
On the other hand, PIV measurements using nozzle S73 at a submergence depth of $90 \mathrm{~mm}$ indicated radical changes of flow patterns and magnitudes of velocities in the field.

Certainly, Figures 17(a) through (d) show the velocity fields corresponding to the same times extracted at the instant when radical flow changes were identified. Although the magnitudes of the velocity vectors are small (the flow plane marked A in Figure 14(c)), it is evident that changes of flow patterns and velocity magnitudes are more extreme using nozzles S73 at the shallow position. Indeed, there are instants when water flows clearly upward, introducing instability to the meniscus; something that was not observed using nozzle S60 at either submergence or even using nozzle S73 at a submergence of $135 \mathrm{~mm}$. These results represent the clearest evidence so far for the existence of a direct relation between the dynamics of the flow in the upper flow region and instability of the meniscus, although this is still inconclusive.

Finding for other direct evidence includes the analysis of results corresponding to experiments consisting of an oil layer placed over the water meniscus, using nozzle S73 at a submergence depth of $90 \mathrm{~mm}$. In these experiments, the motion of the water-oil interface was video recorded during a total time of 7 minutes. Close examination of these videos made it possible to identify cyclic strong interface instabilities of a very short life and low frequency characterized by the entrainment of oil at an intermediate distance between the nozzle wall

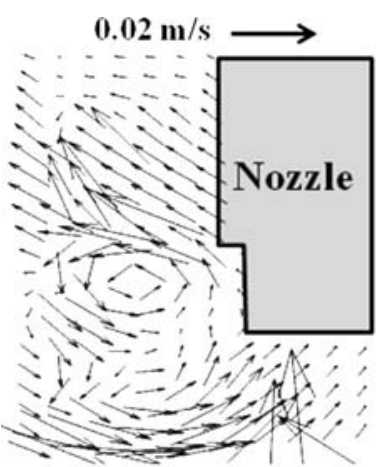

(a)

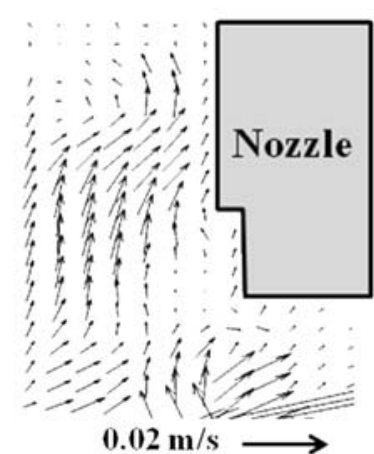

(c)

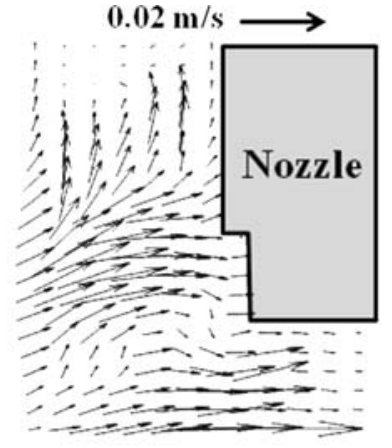

(b)

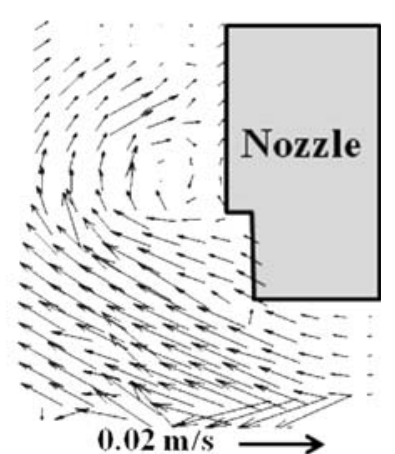

(d)
Fig. 17-Instantaneous velocity vectors measured by PIV, S60 $90-\mathrm{mm}$ immersion. A central-symmetric plane perpendicular to the radius. There is a second between each $(a)$ through $(d)$. 
and the inner face of the mold. Cycle frequency and intensity of velocity spikes were not regular during the experimental time and varied from approximately 110 to 145 seconds. Figures 18(a) through (d) show photos extracted form the video recordings during one of these cyclic instabilities at the beginning of the disturb, 0.30 , 1.0 , and 1.30 seconds later, respectively. Thereby, the duration of this instability lasts only little more than 1 second and repeats itself within the rank of times mentioned previously. Very probably, the radical flow changes reported by Figures 17(a) through (d) include at least partially the effects of this fluid flow disturb, which is responsible for the interface instability and the consequent entrainment of oil into the water bulk. Interpretation of these radical flow changes in Figures 18(a) through (d) is possible through the vorticity of the flow defined as

$$
\zeta=\nabla \times \mathbf{V}
$$

which has a direct relation with the rotation rate of the fluid in two-dimensional field, as provided by PIV measurements $\omega$ through

$$
\zeta_{z}=\left(\frac{\partial v}{\partial x}-\frac{\partial u}{\partial y}\right) \mathbf{k}=2 \boldsymbol{\omega}
$$

Thus, angular velocity is half of the vorticity, and for convention positive vorticity means a counterclockwise rotation and a negative one corresponds to a clockwise rotation. Figures 19(a) through (d) show the instantaneous vorticity fields corresponding to the instantaneous velocity fields presented in Figures 18(a) through (d).
At the beginning of the disturb (Figure 19(a)) vorticity structure includes positive and negative magnitudes with high intensity close to the step of the nozzle wall coexisting with a large negative vorticity in the upper neighbor region. The next time (Figure 19(b)) shows a vorticity distribution, mostly positive, of relatively large magnitudes. However, in the next two time steps (Figures 19(c) and (d)), there is clearly a coexistence of negative and positive vorticities with large gradients, especially close to the step of the nozzle wall.

It is concluded that affectation of meniscus stability is due to the interaction of the turbulent streams in the mold with the fluid located in the upper bath. The fluctuating nature of the flow inside the mold eventually will generate complex vorticity structures, which will disturb the usually quiet flow conditions close to the meniscus. Thereby, a stable meniscus, as observed when nozzle S60 is used, is a consequence of flows without large vorticity gradients in the upper flow approaching irrotational flow conditions. Moreover, there is a relation of the interface instability with the dynamic behavior of water level in the mold. Indeed, Figure 20 shows this relation for both nozzles at a submergence depth of $90 \mathrm{~mm}$. These results make clear that nozzle S60 yields larger water level oscillations than nozzle S73, but do not induce any water level spike as the later nozzle does. These experimental findings lead to the conclusion that this flow disturb is responsible for the flux entrainment in the actual caster.

It is worthy to mention that CFD simulations were not useful to clearly identify the existence of the interface instability when the fluid is discharged by nozzle S73 located at a submergence of $90 \mathrm{~mm}$. Trying

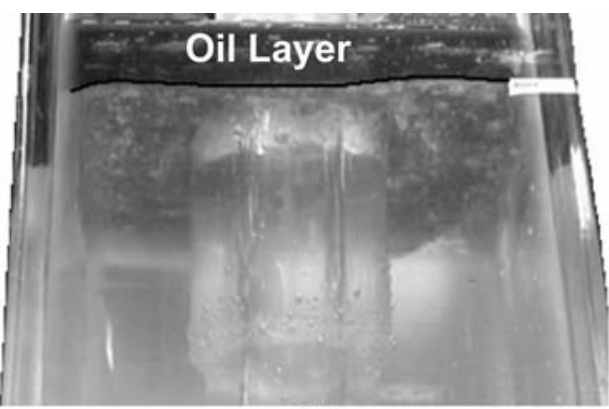

(a)

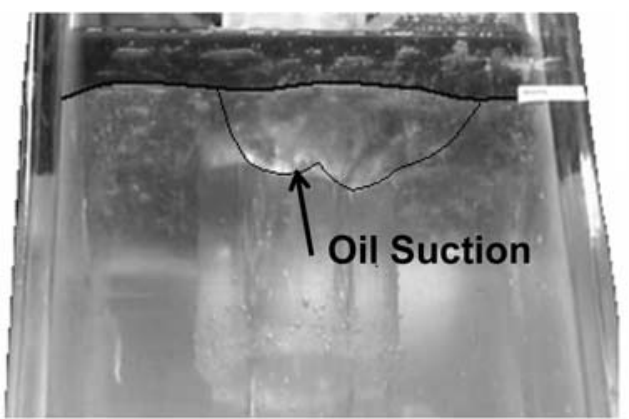

(c)

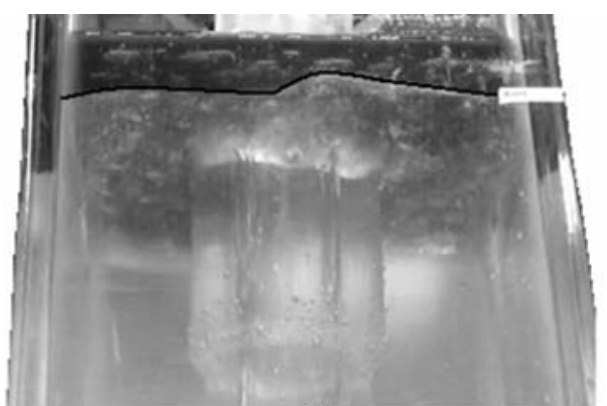

(b)

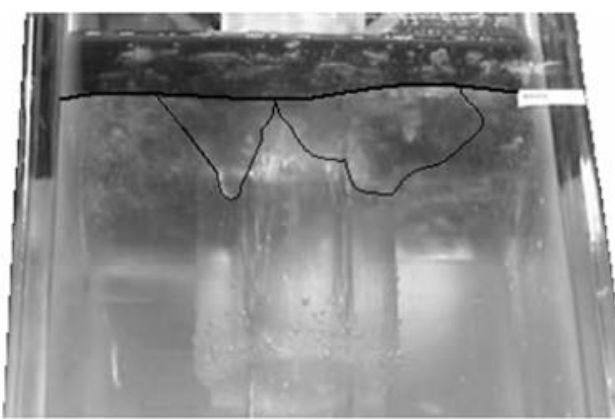

(d)

Fig. 18-Water-oil interface instability development: $(a)$ starting time; $(b)$ after $0.30 \mathrm{~s}$, maximum interface distortion; $(c)$ after $1 \mathrm{~s}$, oil is suctioned into water bulk; and $(d)$ after $1.3 \mathrm{~s}$, oil suction reaches a maximum depth into bath. 


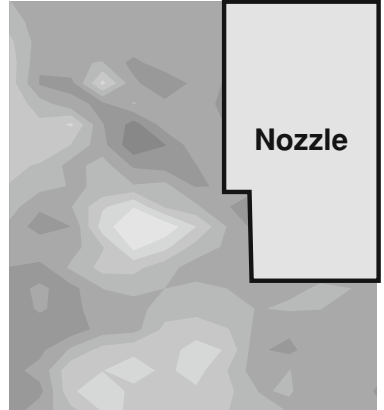

(a)

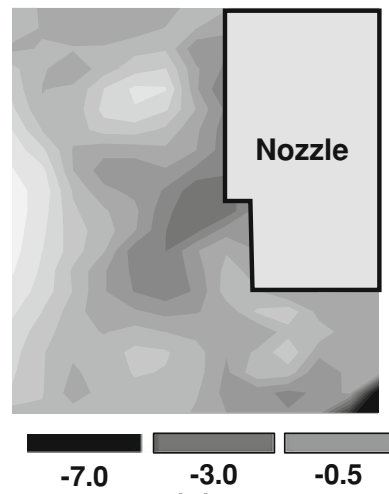

(c)

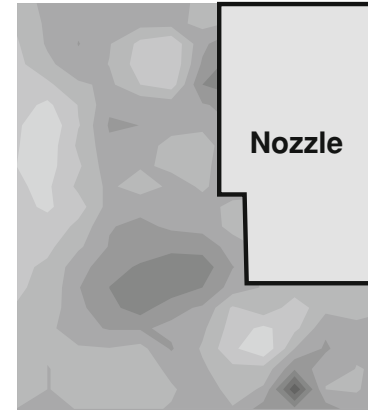

(b)

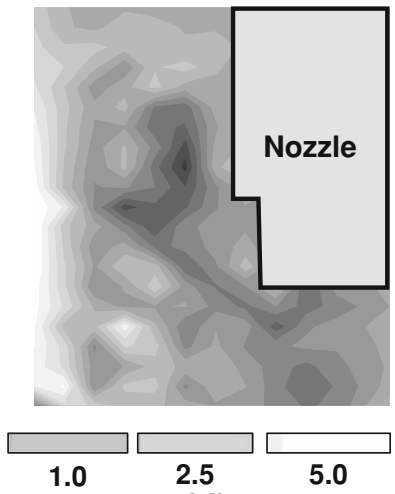

(d)
Fig. 19-Instantaneous vorticity fields measured by PIV, S73 90-mm immersion. A central-symmetric plane perpendicular to the radius. There is a second between each $(a)$ through $(d)$.

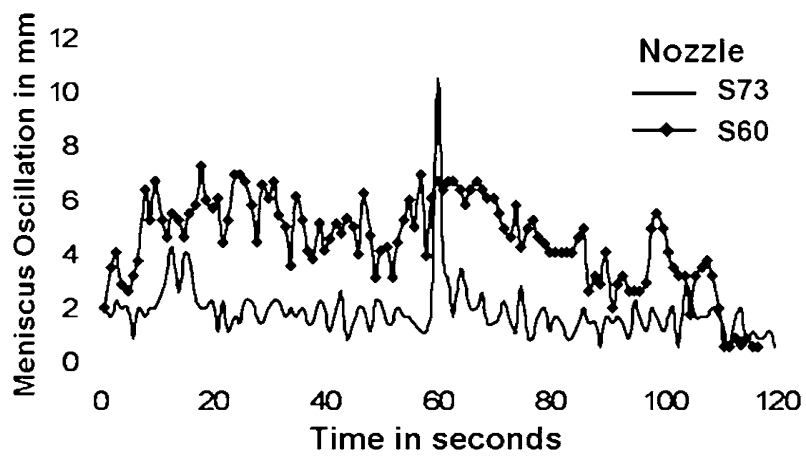

Fig. 20-Meniscus oscillation of water bath in the mold.

to find possible explanations for this mismatching may include an unsuitable size of the computational mesh, an inappropriate turbulence model employed in these simulations, the convergence criterion, or even the computational algorithm employed in these calculations. However, there is still a more elemental answer related with the fact that the flow fields were recorded every 20 seconds instead of every second or even with a higher recording frequency. But this action would require an enormous computer memory and long computing times. Indeed, after a cumbersome review of the velocity fields recorded in the computer files for the first 5 minutes, it was not possible to identify the velocity spikes found by PIV measurements and reported in Figures 17(a) through (d). The only slight evidence provided by CFD simulations was shown in Figures 14(a) through (d) and was already discussed.

Flux entrainment mechanism is complemented through the simulation of flux infiltration through the gap between the strand and the shell. For that purpose, multiphase flow simulations of momentum, mass, and heat transfer including flux, air, and liquid steel were performed. The heat-transfer model takes into account the evolution of latent heat by steel solidification at the mushy zone in addition to heat transfer in the bulk of liquid steel.

Properties of steel and air employed in this model are shown in Table II and properties of the flux are reported in Table I. Details of this model can be consulted in References 24 and 25. The only simplification of this model is that the oscillation of the mold is not considered. Even so, it is capable to provide basic information about the complex multiphase heat, momentum, and mass transfer phenomena taking place inside the mold. Since the computing time is very long, the simulations performed were not concluded to an end and only the first 60 seconds in the real time domain after the flux addition in the mold were simulated. The results are presented in Figures 21(a) and (b) for nozzle S60 at submergences of 90 and $135 \mathrm{~mm}$, respectively, and in Figures 21(c) and (d) for nozzle S73 at submergences of 90 and $135 \mathrm{~mm}$, respectively. Flux infiltration is very fast through the mold corners; however, there are appreciable differences among the four cases studied in this work.

Using nozzle S60 at submergences of 90 and $135 \mathrm{~mm}$ yields an even flux infiltration through the four corners of the mold. When nozzle S73 delivers steel at a submergence of $90 \mathrm{~mm}$ (Figure 21(c)), an uneven flux infiltration is clearly observed. Higher flux infiltration is identified through the two corners of the inner mold face. Therefore, steady flow conditions operating in the mold push the flux from the outer mold side toward the inner mold side producing an overflow. This excess of flux in the inner radius mold side at the instant when the flow disturb comes facilitates flux entrainment by the liquid steel. That is exactly what was visually observed during the water-oil experiments and reported in Figure 18. When the level of submergence of nozzle S73 is increased to $135 \mathrm{~mm}$, flux infiltration becomes more unevenly distributed among the four corners but the momentum of steel arriving to the upper bath surface does not have enough momentum to entrain flux particles.

Therefore, the role of fluid flow on the generation of a strong and periodical disturb of the metal-flux interface when nozzle S73 is located at the shallow position, together with the flux infiltration pattern described previously, give a plausible explanation for flux entrainment into the metal bulk. Based on these results it was possible to establish final recommendations to the caster as follows.

(1) When using nozzle S73 the shallow position must be avoided. Further experiments in the water model demonstrated that the minimum submergence to avoid flux entrainment must be $100 \mathrm{~mm}$. 


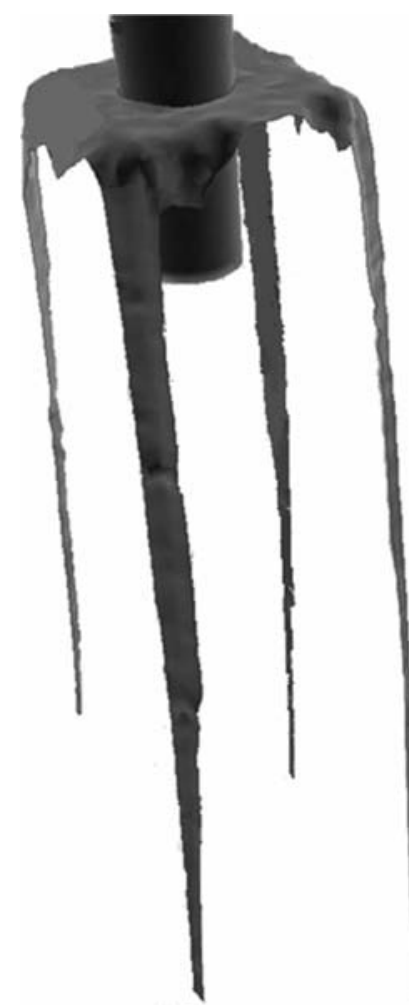

(a)

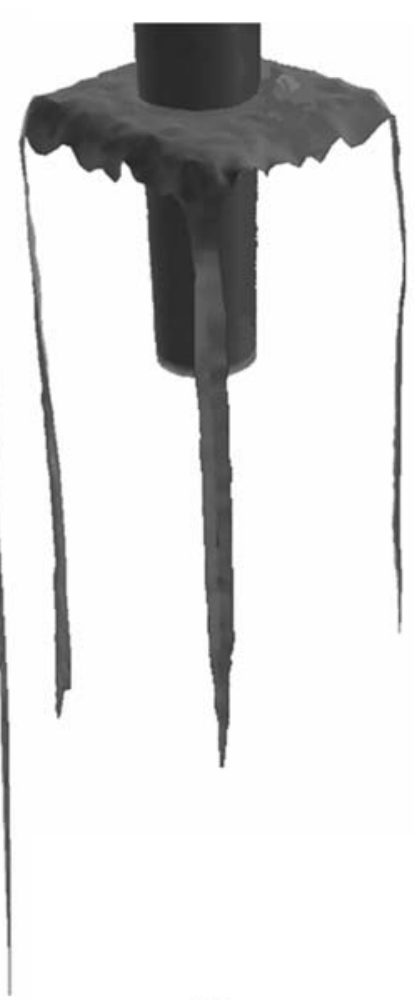

(b)

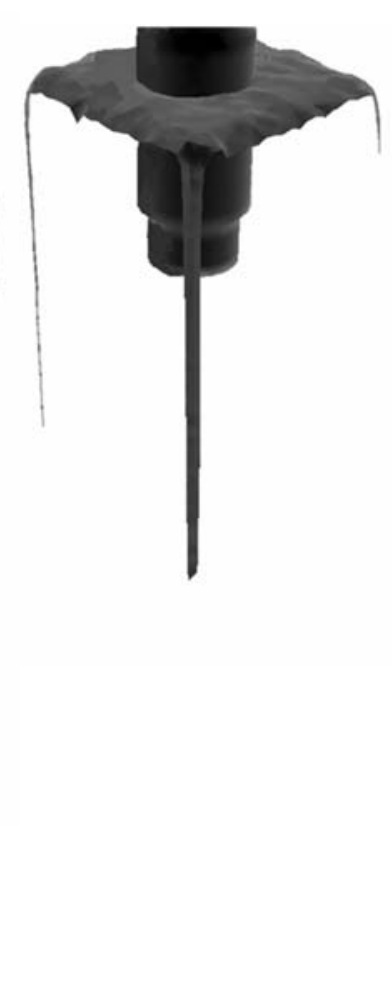

(c)

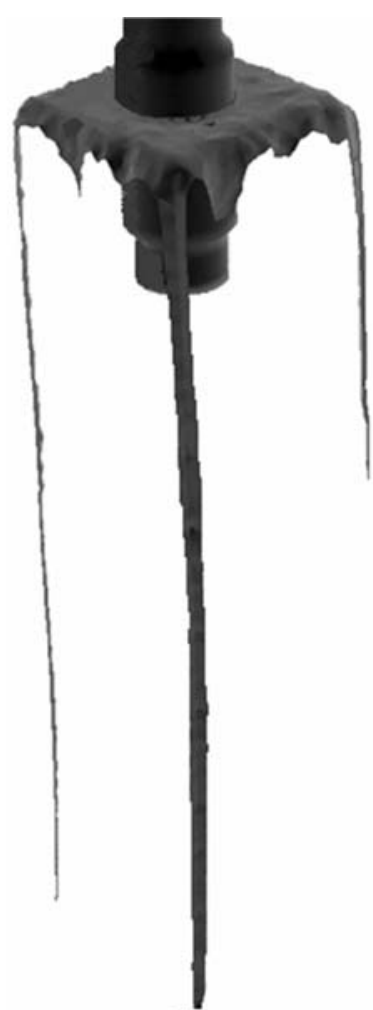

(d)

Fig. 21-Flux infiltration between hot face and shell: (a) S60 90-mm immersion, (b) S60 135-mm immersion, (c) S73 90-mm immersion, and (d) S73 135-mm immersion.

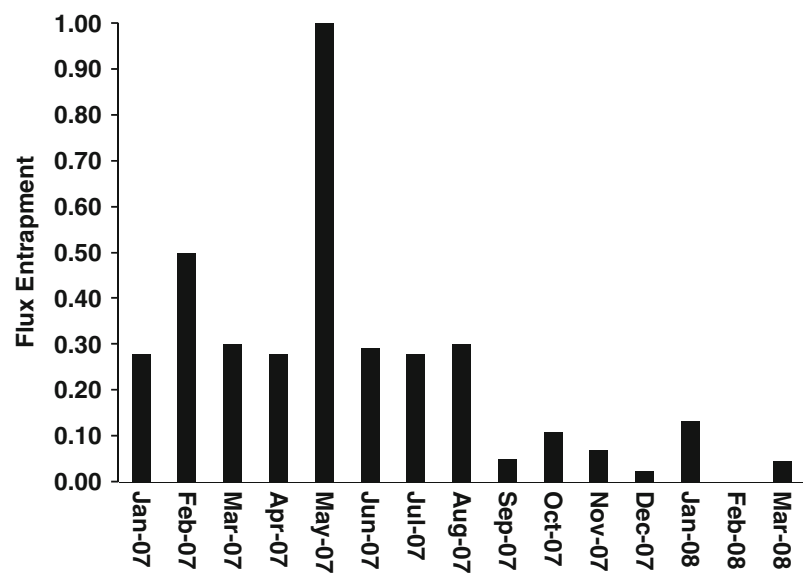

Fig. 22-Evolution index of billets with flux inclusions.

(2) The disadvantage of nozzle S60 is that its thinner wall stands shorter casting sequences, and naturally nozzle S73, due to its larger wall thickness, stands for longer casting sequences. A trade-off between these two characteristics will provide optimum operating conditions.

(3) Nozzle S60 can be used between the ranks of submergences from 90 to $135 \mathrm{~mm}$ safely without any danger of flux entrainment using mold flux (Table I).
It is certain that even these complex mathematical simulations and physical model studies do not stand for rigorous predictions of the current steel flow and solidification phenomena in the current mold. Indeed, there are always limitations when indirect methods are used to analyze complex processes such as continuous casting of steel. However, after the applications of these recommendations the flux entrainment index (calculated considering the highest frequency of product rejected by flux entrainment in a monthly basis as one) decreased considerably, as is reported in Figure 22.

\section{CONCLUSIONS}

Using various types of experiments in a physical water-model and computer fluid dynamics simulations, the fluid flow in a billet caster mold was characterized and the source of flux entrainment defects was identified. The conclusions that can be drawn from this study are as follows.

1. Mold radius induces a strong asymmetry of fluid flow originating recirculation flows in the sides of the inner and outer mold radius.

2. In the region close to the meniscus, there are apparently low turbulence flows; however, this condition is considerably affected by those recirculating flows, specifically when the larger nozzle outer diameter is used at a low submergence. 
3. The origin of the strong disturb at the water-oil interface or scaling up to the real conditions at the metal-flux interface is due to fluid velocity vectors completely oriented toward this interface interacting with mold flux. The recirculating flow in the lower mold side pushes flux toward the side of the inner mold face forming and excess of flux. Momentum transfer of steel at the instant of that disturb when $\mathrm{S} 73$ is located in the shallow position is large enough to entrain flux particles.

4. During mold operation, nozzle S60 promotes higher liquid level oscillations than nozzle S73, but this later induces velocity spikes at a shallow position.

5. The intensities of those recirculating flows increase as the gap between the mold face and the nozzle wall decreases.

\section{ACKNOWLEDGMENTS}

The authors thank Consejo Nacional de Ciencia y Tecnologia (CoNaCyT) for the scholarships granted to ETR and SHG to perform their graduate studies at IPN. They also thank Sistema Nacional de Ciencia y Tecnologia (SNI), Comision de Fomento para las Actividades Academicas (COFAA), and Ejecucion de Desarrollo e Invstigacion (EDI) for their financial support.

\section{REFERENCES}

1. B. Zhao, B.G. Thomas, S.P. Vanka, and R.J. O'Malley: Metall. Mater. Trans. B, 2005, vol. 36B, pp. 801-23.

2. C.H. Moon and S.M. Hwang: Ironmaking and Steelmaking, 2003, vol. 30 , pp. $48-56$.

3. H. Yang, L. Zhao, X. Zhang, K. Deng, W. Li, and Y. Gan: Metall. Mater. Trans. B, 1998, vol. 29B, pp. 1345-36.
4. Q. Yuan, T. Shi, S.P. Vanka, and B.G. Thomas: Proc. Comp. Modeling of Materials, Minerals and Metals Processing, Cross, Bailey, and Evans, eds., TMS, Warrendale, PA, 2002, pp. 491-500.

5. S. Kunstreich and P.H. Dauby: Ironmaking and Steelmaking, 2005, vol. 32, pp. 80-86.

6. S. Ogibayahsi: Proc. Process Technology Conf., ISS, Pittsburgh, PA, 1995, vol. 13, pp. 33-42.

7. P. Andrzejewsky, D. Gothelff, E. Julius, H. Haubrich: Proc. Steelmaking Conf., Warrendale, PA, 1997, vol. 80, pp. 153-58.

8. K.H. Moon, C.H. Lee, P.R. Cha, J.Y. Chung: Proc. Steelmaking Conf., Warrendale, PA, 1997, vol. 80, pp. 173-82.

9. S.H. Seyedin and M. Hasan: Int. J. Heat Mass Transfer, 1997, vol. 40, pp. 4405-23.

10. S.K. Choudhary, D. Mazumdar, and A. Gosh: ISIJ Int., 1993, vol. 33, pp. 764-74.

11. M.R. Aboutalebi, M. Hasan, and R.I.L. Guthrie: Metall. Mater. Trans. B, 1995, vol. 26B, pp. 731-44.

12. X.K. Lan, J.M. Khodadadi, and F. Shen: Metall. Mater. Trans. B, 1997, vol. 38B, pp. 321-32.

13. J. Szekely and R.T. Yadoya: Metall. Trans., 1972, vol. 3, pp. 267380.

14. J. Szekely and R.T. Yadoya: Metall. Trans., 1973, vol. 4, pp. 1379 88 .

15. D. Xu, W.K. Jones, Jr., J.W. Evans, and D.P. Cook: Appl. Math. Model., 1998, vol. 21, pp. 883-93.

16. M. Raffel, C. Willert, and J. Kompenhans: Particle Image Velocimetry, Springer-Verlag, New York, NY, 1998, pp. 20-178.

17. W.P. Jones and B.E. Launder: Int. J. Heat Mass Transfer, 1972, vol. 15 , pp. $301-14$.

18. D.C. Wilcox: Turbulence Models for CFD, D.C. Industries, La Cañada, CA, 2000, pp. 1005-16.

19. P. Ramirez-Lopez, R.D. Morales, R. Sánchez-Pérez, L.G. Demedices, and O. Davila: Metall. Mater. Trans. B, 2005, vol. 36B, pp. 787-99.

20. P. Ramirez-Lopez and R.D. Morales: Ironmaking and Steelmaking, 2006, vol. 33, pp. 157-68.

21. J.H. Ferziger and M. Peric: Computational Methods for Fluid Dynamics, Springer, Berlin, New York, NY, 2002, pp. 270-320.

22. R.B. Byrd, W.E. Stewart, E.N. Lightfoot: Transport Phenomena, Wiley-Toppan, New York, NY, 1960, pp. 123-270.

23. S.V. Patankar: Numerical Heat Transfer and Fluid Flow, McGrawHill Books, New York, NY, 1980, pp. 83-176.

24. P. Ramirez-Lopez: M.Sc. Thesis, Instituto Politecnico NacionalESIQIE, Mexico, 2006.

25. R.D. Morales and P. Ramirez-Lopez: Proc. Steelmaking Conf., AIST, Cleveland, OH, 2006. 